\title{
ON THE DEVELOPMENT OF THE PULMONARY CIRCULATION IN THE CHICK
}

\author{
THEODORE L. SQULER \\ From the Zoological Laboratory of the University of Michigan \\ THREE TEXT FIGURES AND TWO PLATES
}

INTRODUCTION

Although the chick long ago achieved the position of a classic in embryological studies, certain crucial details in the establishment of its pulmonary circulation have been left in the greatest obscurity. The textbooks for many years have been giving accounts, adequate enough, of the origin of the pulmonary artery, but the development of the corresponding vein has for the most part been mentioned only incidentally in connection with hatching (Lillie). Even with respect to the arterial course in the lung proper, particularly its relation to the capillary system, there remains doubt, for the exact time and mode of completion of this portion of the circuit has not been directly determined in the chick, nor for the most part as closely inferred from investigations on other forms as it might have been. It was for these reasons that I began an investigation of this subject at the suggestion and under the direction of Professor Otto C. Glaser.

\section{METHODS AND RESULTS}

The first stage of which I made injections was the 96 hour embryo. If the pulmonary circuit is complete at this time it should be possible to inject the vessels from the vitelline artery or vein. Accordingly, while the embryonic heart was still beating, india ink was injected through the vitelline artery by Knower's bulb method (Knower, '08). Care was used, of 
course, not to injure the vitelline vessels at any time, and by keeping the embryo covered as much as possible with warm saline solution the heart action was prolonged and better injections secured. The injected chicks were fixed in Bouin's fluid, stained with borax-carmine, and after imbedding in paraffin cross sections were cut $10 \mu$ thick.

A cursory examination of such sections prepared from a 96 hour embryo (the length determined from the number of sections was $9.64 \mathrm{~mm}$.) at once showed that the ink had entered all the smaller vessels, and about the lung rudiments a large number of injected capillary tubules were found. From this it is conclusively shown that a very considerable portion of the pulmonary circuit is complete at this time, but whether the entire course is complete and what its exact relations to the rest of the circulatory system are, could only be determined by means of reconstructions.

Because of the minuteness of the structures under consideration, reconstructions in wax could not be undertaken. Instead, the graphic method was resorted to with entirely satisfactory results. I reflected the sections at 300 diameters magnification and outlined the lungs and the surrounding vessels. Then by projecting each of these separate drawings the final reconstruction reproduced in plate 1 was completed. The drawing represents the left lung rudiment and its surrounding plexus of vessels viewed from the medial surface. The right rudiment corresponds so closely to the left with respect to the number and development of pouches as not to warrant a separate description. Throughout I will designate that side of the lung rudiment which faces the middle line of the embryo as the medial surface and the side directed away from the middle line will be spoken of as the lateral surface.

The left lung rudiment at 96 hours consists of three well marked pouches budding from the dorsal side of the bronchus. The first, or most anterior of these, plate $1, g$, is the largest. The second and third, $h$ and $i$, decrease rapidly in size. Posterior to the last pouch, $i$, a broad swelling dorsal in position denotes the beginning of a fourth pouch. 
The rudiment in question extends through 143 sections, that of the right lung through 135 sections ( $10 \mu$ thick) counting from the bifurcation of the bronchus. Anteriorly the pulmonary artery forms an extensive plexus, $p$, the principle portion of which lies dorsal to the bronchus. One arterial branch, $s$, courses in a ventral direction from the plexus around the median surface of the bronchus and closely approaches a dorsally directed vessel, $r$, itself a tributary of the median cranial vessel, $t$, which joins the left pulmonary vein just before this unites with the corresponding vein on the right. Such an arrangement is certainly very suggestive of a previous anastomosis between artery and vein. From the cranial plexus, $p$, the lung artery, $a$, proceeds along the external surface of the bronchus and is unbranched until the expanded portion of the lung proper is reached. Immediately before reaching the lung the artery is quite small. It continues along the dorso-lateral surface of the lung rudiment in nearly a straight line and gives off two branches the first of which, plate $2, j$, provides for the most anterior lung pouch, while the second branch, $k$, provides for both the second and third pouches. Distally the artery anastomoses with the vein in the region indicated by $x$ in plate 1 , and also it gives off two lateral branches shown at $l$ and $m$ in plate 2 which end blindly-

On the ventro-medial surface of the lung rudiment three main venous lines of drainage $(u, v, w$, plate 1$)$ are established. The anterior vessel, $u$, is the largest, as would be expected, since it drains the oldest and largest of the bronchial pouches. The other two veins show a decrease in size corresponding approximately to the decrease in size of the vesicles which they drain. The left tributary, $d$, of the pulmonary vein, formed by the union of the three lateral vessels, turns ventro-medially from the bronchus at an abrupt angle to unite with the corresponding venous tributary from the right lung. The common stem thus formed follows a nearly straight course ventralward and empties into the left auricle of the heart as described by Federow in the case of a duck of 4 days, 13 hours: "Die Einmündung der Vene durchbohrt den Vorkammerschiedewandgrund schräg 
und öffnet sich an der linken Seite des Septum. Dasselbe ist mit dem Vorkammerboden verschmolzen."

No caudal connection exists between the splanchnic plexus and the vessels of the lungs, and in this stage no trace of such connection is indicated.

In order to verify the essential correctness of the reconstruction, I cut sagittal sections $200 \mu$ thick of a 96 hour injected embryo. The result was very satisfactory indeed, since the sections were thick enough to show the course of the circulatory vessels even more clearly than would actual dissection of the organs concerned. The thickness of the sections precluded the possibility of counting the secondary lung vesicles or pouches. The general course of the vessels is the same as found in the reconstruction. Several features of the cranial arterial plexus are shown here (fig. 1) however, that are omitted in the reconstruction owing to the fact that the latter does not include the most anterior part of the plexus. The artery, $a$, sends a single dorsally directed branch, $e$, to the gut. Near this dorsal branch two ventral branches are given off and the anterior of these, $j$, branches immediately into two stems which eventually anastomose with a plexus that empties into the median cranial branch of the pulmonary vein. Cranially an intricate dorsal plexus, $d$, is given off by the artery and its anastomosing branches extend cephalad possibly as far as the level of the first gill arch (compare with $p$, plate 1 ). The plexus, $f$, surrounding the lung proper is very similar to that found in the reconstruction. The artery, $a$, follows the dorsal surface of the bronchus (in the figure faintly indicated by a slightly darker area) as described in the preceding embryo, and between the last cephalic branch, $s$, and the level of the lung proper it is unbranched and of uniform diameter. In the section next adjoining that figured a small caudally directed branch arises from the common stem of the pulmonary vein near the union of the right and left main tributaries and anastomoses with the plexus of blood vessels surrounding the gut posterior to the lungs. The same section also shows the median-cranial tributary of the vein and its arterial anastomosis already described in the preceding embryo. 
In the 96 hour chick then, the pulmonary circulatory system is complete. The vein stem which empties into the right auricle proceeds dorsally for a short distance and then branches into right and left veins which drain the corresponding lung rudiments.

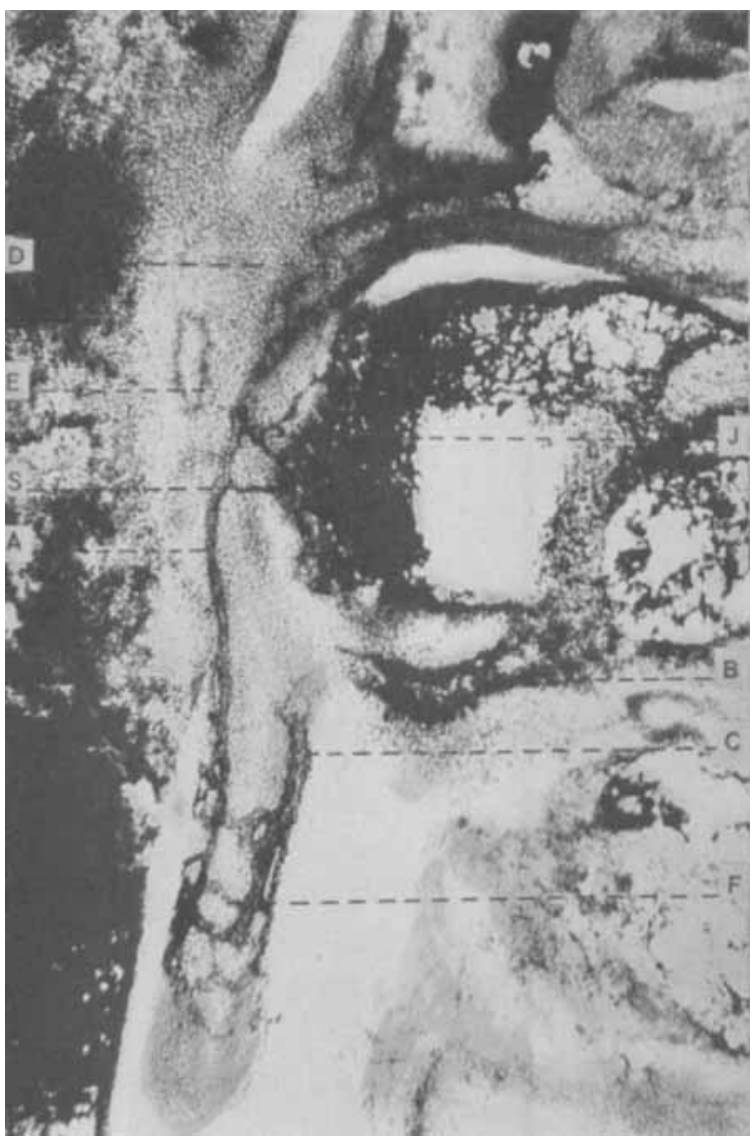

Fig. 1 Photograph of sagittal section $200 \mu$ thick of injected 96 hour chick showing general course of right artery and vein together with plexus surrounding the right lung rudiment; $\times 97$. a, pulmonary artery; $d$, cephalic plexus surrounding gut; $j$, arterial stems that anastomose with the median cranial vein tributary (not shown); $b$, common stem of pulmonary vein; $c$, left pulmonary vein; $f$, plexus surrounding the right lung rudiment. Region of bronchus and lung rudiment is indicated by the dark area in the neighborhood of the plexus, $f$, and the pulmonary artery. 
The left vein, near its union with the right, receives a tributary which runs in a cranial direction midway between the lung rudiments and which forms anastomoses with ventrally directed branches from the lung artery. These anastomoses may or may not persist at 96 hours.

Sections $10 \mu$ thick were prepared from a 72 hour injected embryo measuring $6.56 \mathrm{~mm}$. (the length was determined from the number of sections). The lung anlage consists of a right and left primary rudiment. No secondary lateral vesicles are present. The distal ends of the primary bronchi are slightly swollen into pouches. The common stem of the pulmonary vein empties into the left side of the sinus venosus at $b$, figure 2 . From this point the vein stem runs dorsalward for a short distance and then receives its right and left tributaries, $c$ and $d$, which drain the ventral sides of the right and left lung vesicles respectively, where, as clearly shown by the injections, they form capillary baskets distinguished from those of the 96 hour stage by greater simplicity.

Just before the confluence of right and left veins, a comparatively large vessel empties into the dorsal side of the common pulmonary stem. This last named tributary runs to the ventral side of the gut where it branches and the two veins (e, fig. 2), after forming anastomoses with branches from the pulmonary arteries, parallel each other in a caudal direction until the level of the distal ends of the lung rudiments has been reached. Here their identity becomes lost in a general plexus surrounding the gut

Frontal sections $200 \mu$ thick of this stage were also cut. The lung anlagen are in about the same stage of development as in the 72 hour embryo just described. The right and left primary lung vesicles as shown in figure $3, l$, are without secondary pouches, and the distal end of each is slightly swollen. The common stem of the pulmonary vein receives the right and left vessels, $d$ and $c$, at a point midway between the two primary vesicles, and nearly midway between the proximal and distal ends of the bronchi. In addition to the main vessels draining the right and left lung rudiments, two cephalic branches arise from the common stem. The branch, $g$, which lies to the left, 
leaves the stem vein without dividing, while the other, $h$, which is considerably larger, bifurcates almost immediately. All of these vessels run eranialward along a median line between the bronchi. Near the proximal end of the left bronchus a lateral branch, $j$, from the left pulmonary artery crosses the dorsal surface of the bronchus and anastomoses with the cranial end

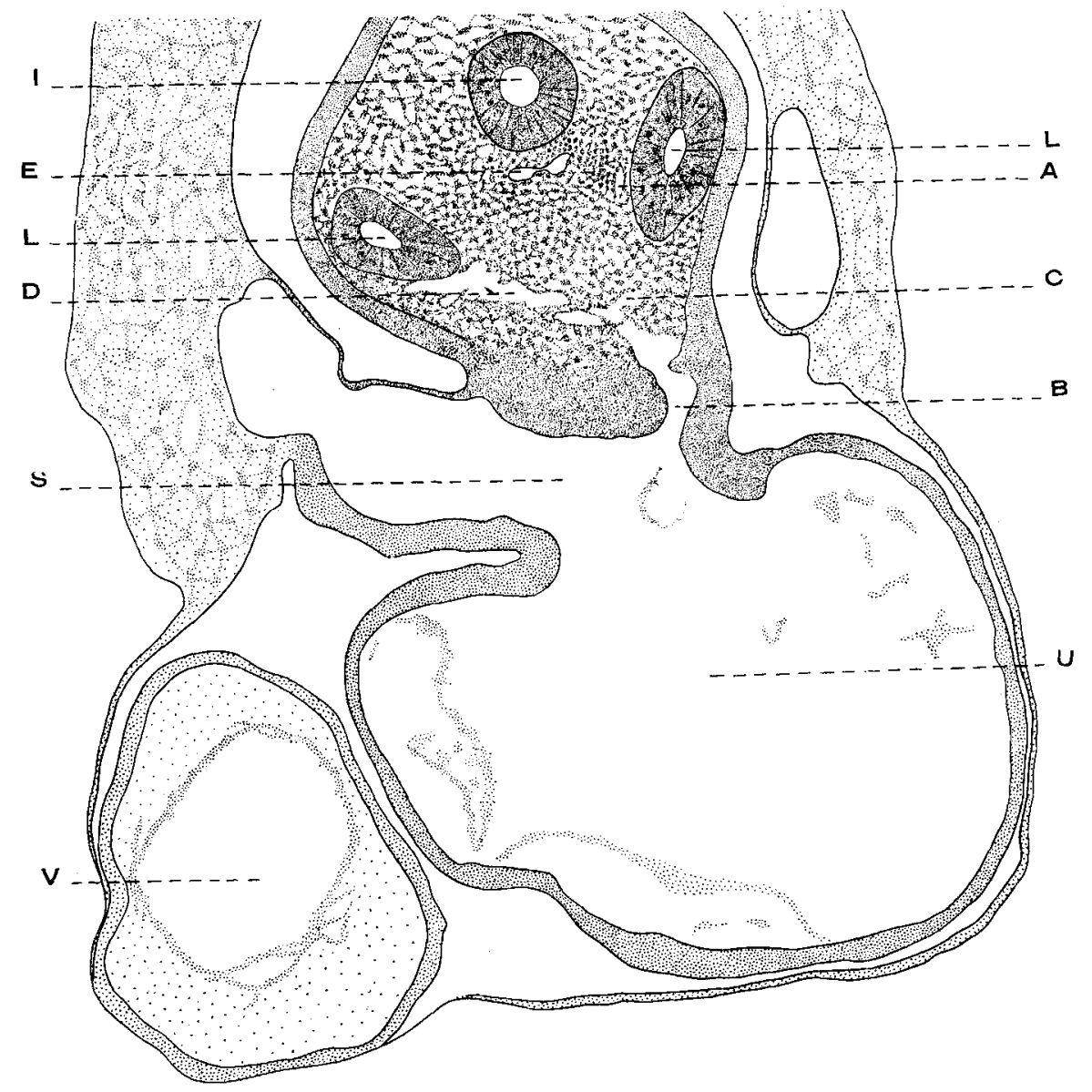

Fig. 2 Cross section of 72 hour chick through region of the sinus venosus and mouth of the pulmonary vein; $\times 120 . \quad u$, auricle; $v$, ventricle; $b$, common stem of pulmonary vein; $s$, sinus venosus; $c, d$, left and right pulmonary veins respectively; $a$, left pulmonary artery; $e$, median vein tributaries; $l$, bronchus; $i$, gut. 


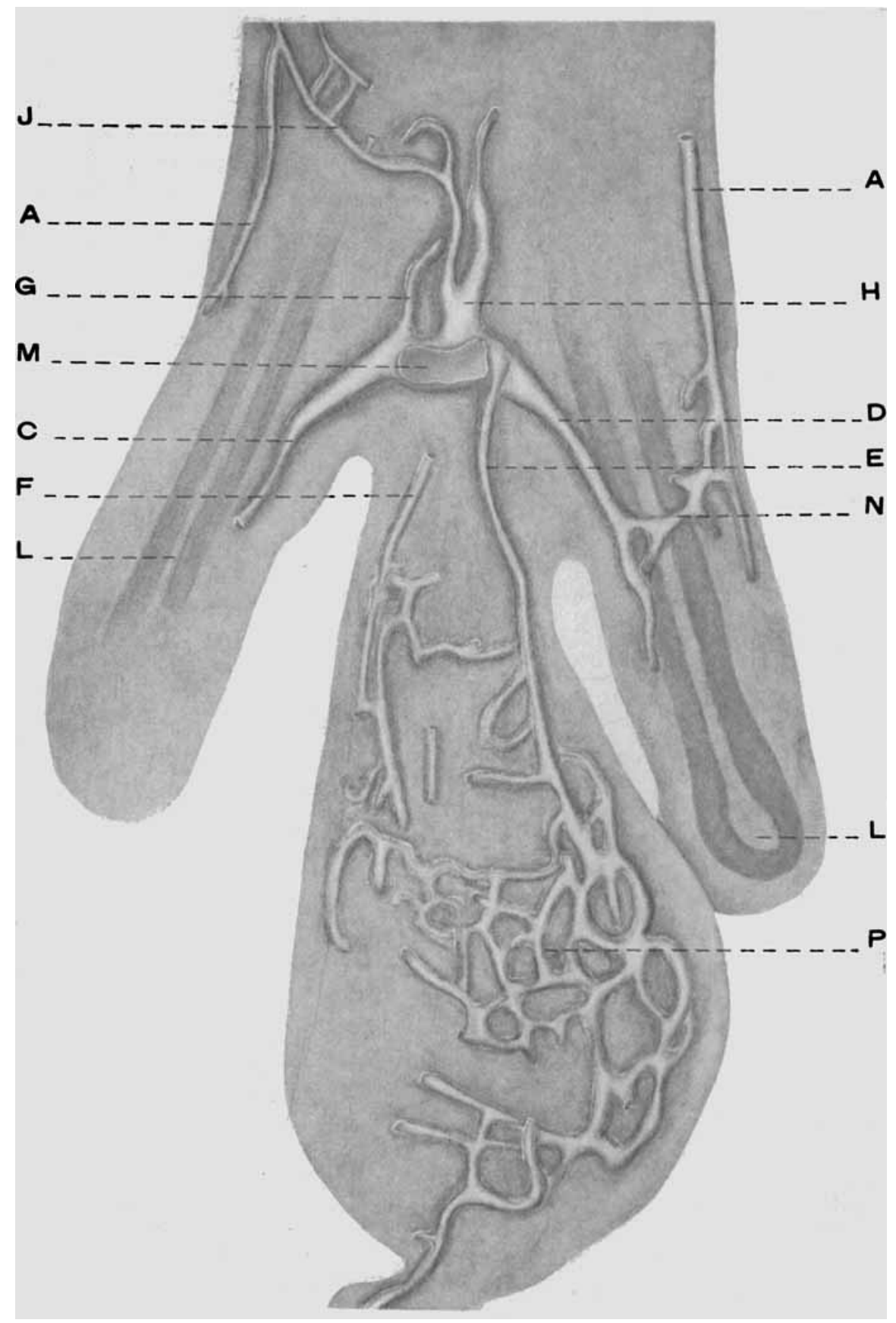


of one of the median vein branches. A caudal branch, $e$, is also present, which connects the pulmonary vein with a well developed plexus, $p$, surrounding the posterior portion of the gut.

The vessel, $e$, connecting the gut plexus, $p$, with the right pulmonary vein is very minute and in the preparation was but slightly injected. The exact relations of the corresponding vessel, $f$, on the left have not been determined. Whatever they may be, the evidence from the size of these veins indicates that at 72 hours the blood current flowing between this splanchnic plexus and the pulmonary veins is feeble. The correctness of this supposition is further indicated by the fact that at 96 hours the connections $e$ and $f$ are either still more weakly indicated or entirely absent. The pulmonary circulation in the 72 hour chick then, is also complete. It differs however from that of the 96 hour stage in two respects: the capillary baskets around the lung rudiments proper are simpler, but the accessory and secondary connections such as those with the splanchnic plexus are more numerous. Furthermore the median cranial tributaries of the pulmonary veins in comparison with the main right and left vein trunks in the 96 hour chick are much larger and as in this latter stage anastomose with the lung arteries.

\section{DISCUSSION}

That the pulmonary circuit is complete, though not necessarily in its definitive form in the 72 hour chick is not open to doubt. Granted only that it undergoes gradual correlative metamorphosis during the remainder of the period of incubation, there is left no reason for expecting a circulatory crisis at hatching. The success of my injections shows conclusively that

Fig. 3 Frontal section $200 \mu$ thick of injected 72 hour chick; $\times 120 . m$, mouth of common pulmonary vein; $d, c$, right and left pulmonary veins; $g, h$, median cranial tributaries to common vein; $j$, lateral branch of artery forming anastomosis with median cranial vein; $\alpha$, pulmonary artery; $n$, small portion of plexus of vessels surrounding right lung rudiment; $l$, lung rudiment areas indicated by deeper shading; $e$, caudal tributary to pulmonary vein; $f$, probably a tributary to pulmonary vein with a connection similar to that of $e ; p$, plexus surrounding gut. 
blood must flow through the pulmonary system at a very early stage, although owing to relative resistances in this and the general systemic circulation the amount passing through the lungs is undoubtedly small. With the general enlargement of the pulmonary system, and finally upon collapse of the last aortic arch, a circuit adequate for respiratory purposes is not only at hand, but is automatically put in use.

With respect to the early course of the vein and its anastomoses with the artery, several conditions found correspond in general with those of Federow. The close approach of a branch from the median cranial vein to an arterial branch in the 96 hour chick (plate $1, r$ ) has been mentioned above as suggestive of a previous anastomosis which has but recently disappeared. In a duck of 114 hours Federow found a similar condition and says: "Der distale (dem Kopfe nächste) Teil des kranialen Venenastes, der die Anastomosen mit den ventralen Lungenarterien bildet, hat die Verbindung mit dem proximalen Abschnitte des kranialen Astes verloren."

With respect to the anastomosis between the caudal branch from the vein and the plexus surrounding the gut he says:

Ich möchte hier noch erwähnen, dass der kaudale Venenast bei den Vögeln und Säugetieren (bei den ersteren durch die Gefässe der speisröhre) eine Zeitlang mit der hinteren Hohlvene in Verbindung steht. Wenn auch diese Verbindung zwischen den Gefässen von ganz verschiedenen Systemen in der topographischen Nähe und in der sehwachen Differenzierung der Lungo und des Darmkanals an dem betreffenden Stadium eine gewisse Erklärung findet, so stellt sie sich loch sehr bemerkenswert dar. Etwas Ähnliches beobachtet man bei (ler Entwickelung der hinteren Hohlvene, nämlich die Verbindung zwischen der V. omphalo-mesenterica und den Vv. cardinales posteriores.

Federow has dealt at length with the origin of the pulmonary vein and concludes that it is produced at a very early stage of embryonic life as a proliferation of endothelium from the dorsal sinus wall which projects into the dorsal mesocardium. Into this proliferation the sinus cavity tunnels, thus producing a short vessel which is the anlage of the vein. This vein, very near its point of origin from the sinus, branches into two vessels 
whose ultimate divisions terminate in capillary trees that anastomose with capillary outgrowths from the lung arteries. The vein mouth, which at first empties into the sinus, is finally absorbed into its definitive position as a result of unequal growth of the heart wall.

Brown, on the basis of his investigations on the pulmonary system of the domestic cat, disagrees with Federow's view and holds that the pulmonary veins are differentiated out of an indifferent plexus originally present around the primitive gut and from the beginning connected with the sinus. The vessels of this plexus form numerous anastomoses with the surrounding veins and in addition the plexus "exhibits two well defined connections with the venous portion of the heart, (1) the cephalic or pulmonary, and (2) the caudal or postcaval. These are constant both in occurrence and position." According to Brown's view, therefore, the pulmonary vein is simply a specially developed part of an indifferent plexus present from the beginning in the region from which the lungs grow.

My own observations on the development of the pulmonary circulation do not furnish the basis necessary to decide between these opposed views. Concerning the presence of an extracardiac indifferent plexus, as claimed by Brown there is no doubt. The primitive gut is certainly surrounded by a network of capillaries, and it seems probable that as the lung anlage pushes out from the gut a portion of the surrounding capillary plexus would be carried with it. If this capillary system is derived from angioblast originally continuous with that from which the heart itself is formed, it is easy to see how the pulmonary vein might be nothing more than the survival of a pathway rendered permanent in accordance with the mechanical principle that those vessels in which the blood current is strong become permanent whereas those in which it is weak atrophy and eventually disappear (Mall '10). The numerous early connections between pulmonary arteries and veins which for the most part are lost as early as 96 hours seem to harmonize with this interpretation. In the 72 hour chick, in addition to the pulmonary veins, which persist, there are from one to three 
or more branches which run toward the head to form the median cephalic connection with the arteries and caudally one or more vessels connect the vein stem with the plexus of the gut. This latter connection shows signs of atrophy even at 72 hours and in the 96 hour chick from which the reconstruction figured in plate 1 was made it has completely disappeared. The median cranial connections are more persistent and in plate 1 the condition of the vessels indicates that the connection with the left artery has been but recently lost. Accordingly then, the pulmonary vein in the chick could be regarded as complete from the beginning and as representing the sole survivor of numerous primitive vessels that drain the region surrounding the lung anlage.

On the other hand Federow's idea that a median dorsal outgrowth from the sinus connects secondarily with the lung capillaries is not to be set aside lightly. In the first place I have found the outgrowth clearly indicated in embryos earlier than those injected; in the second place its position is identical with that assigned to the earliest indications of the pulmonary vein as given by Brown. It seems quite possible therefore that further investigation might harmonize the two views which so far at least do not necessarily appear mutually exclusive.

In conclusion I wish to acknowledge my indebtedness to Professor Glaser whose suggestions and assistance both in the laboratory work as well as in the preparation of my manuscript have been of the greatest value.

\section{TBIBLIOGRAPHY}

Виемен, J. L. 1902 On the origin of the pulmonary artery in mammals. Amer. Jour. Anat., vol. 1, no. 2.

Brown, A. J. 1910 The pulmonary voin in the domestic cat. Anat. Rec., vol. 7 , no. 9 .

Federow, V. 1910 liber die Entwickelung der Tungenvene. Anat. Hefte, 1 Abt. 122 Heft (40 Bd., H. 3).

FLint, J. M. 1907 The development of the lungs. Amer. Jour. Anat, vol. 6, no. 1 .

KNownr, H. F. 1908 A new and sensitive method of injecting the vessels of small embryos, ete, under the microscope. Anat. Rec., vol. 2, no. 5 .

Litute, F. R. 1908 The development of the chick.

MALL, F. P. 1906 A study of the structural unit of the liver. Amer. Jour. Anat., vol. 5, no. 1 . 
PLATE 1

EXPLANATION OF FIGURF

Reconstruction of the left lung rudiment and accompanying blood vessels of a 96 hour chick viewed from the medial surface; $\times 100$.

$a$, left pulmonary artery

$d$, left pulmonary vein

$g, h, i$, first, sccond and third lung pouches respectively

$j$, blind ventrally directed arteriole

$o$, blind distal arterial termination

$p$, dorsal plexus of artery

$r$, branch from the median cranial tributary of the pulmonary vein

$s$, ventrally directed arterial branch which probably previously anastomosed with the dorsally directed vessel, $r$

$t$, median cranial tributary of the pulmonary vein

$u, v, w$, veins draining first, second and third lung pouches respectively

$x$, distal anastomosis between artery and vein

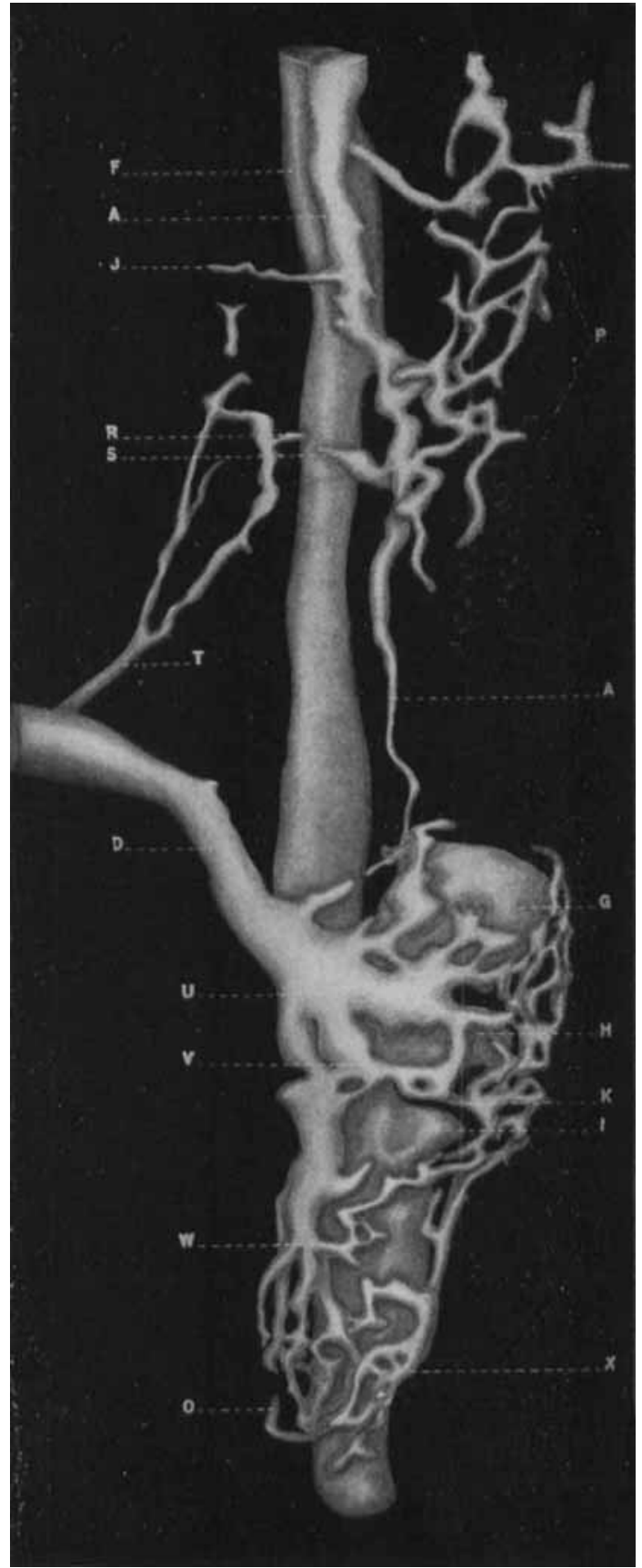

437

THE ANATOMICAL RFCORD, Vol.. 10 , No. 6 


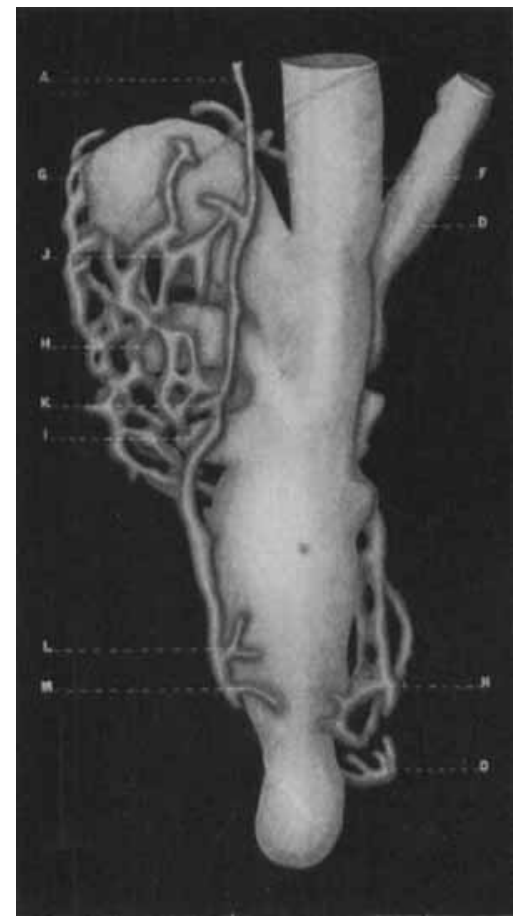

PIATF 2

EXPLANATION OF FIGURF

Reconstruction of the left Iung rudiment and accompanying blood ressels viewed from the lateral surface; $\times 100$.

$a$, left pulinonary artery

$f$, left bronchus

$g, h, i$, first, second and third lung pouches respectively

$j$, arterial branch supplying the first lung pouch $k$, arterial branch supplying second and third lung pouches

$l, m$, lateral blind arterial branches $n$, blind distal termination of vein $o$ blind distal termination of artery 